\title{
Influence of thin film thickness of working electrodes on photovoltaic characteristics of dye-sensitized solar cells
}

\author{
Yeong-Lin Lai ${ }^{1, *}$, Hung-Ru $\mathrm{Hsu}^{2}$, Yeong-Kang Lai ${ }^{3}$, Chun-Yi Zheng ${ }^{1}$, Yung-Hua Chou ${ }^{1}$, Nai-Kun Hsu ${ }^{1}$, and Guan-Yun \\ Lung
}

${ }^{1}$ Department of Mechatronics Engineering, National Changhua University of Education, 50007 Changhua, Taiwan

${ }^{2}$ Green Energy and Environment Research Laboratories, Industrial Technology Research Institute, 31040 Hsinchu, Taiwan

${ }^{3}$ Department of Electrical Engineering, National Chung Hsing University, 40227 Taichung, Taiwan

\begin{abstract}
This paper presents the study of the influence of thin film thickness of working electrodes on the photovoltaic characteristics of dye-sensitized solar cells. Titanium dioxide $\left(\mathrm{TiO}_{2}\right)$ thin films, with the thickness from 7.67 to $24.3 \mu \mathrm{m}$, were used to fabricate the working electrodes of dye-sensitized solar cells (DSSCs). $\mathrm{A} \mathrm{TiO}_{2}$ film was coated on a fluorine-doped tin oxide (FTO) conductive glass substrate and then sintered in a high-temperature furnace. On the other hand, platinum $(\mathrm{Pt})$ solution was coated onto an FTO substrate for the fabrication of the counter electrode of a DSSC. The working electrode immersed in a dye, the counter electrode, and the electrolyte were assembled to complete a sandwich-structure DSSC. The material analysis of the $\mathrm{TiO}_{2}$ films of DSSCs was carried out by scanning electron microscopy (SEM) and ultraviolet-visible (UV-Vis) spectroscopy, while the photovoltaic characteristics of DSSCs were measured by an AM-1.5 sunlight simulator. The light transmittance characteristics of the $\mathrm{TiO}_{2}$ working electrode depend on the $\mathrm{TiO}_{2}$ film thickness. The thin film thickness of the working electrode also affects the light absorption of a dye and results in the photovoltaic characteristics of the DSSC, including open-circuited voltage $\left(V_{\mathrm{OC}}\right)$, short-circuited current density $\left(J_{\mathrm{SC}}\right)$, fill factor, and photovoltaic conversion efficiency.
\end{abstract}

\section{Introduction}

The rapid economic development and rapid population expansion have caused a deteriorating energy problem. The energy problem has a significant impact on industrial development. The BP Statistical Review of World Energy in 2017 reported that by the end of year 2016 , the reserves/production ratio ( $\mathrm{R} / \mathrm{P}$ ratio) in the world for coal was 153 years, for natural gas 52.5 years, and for oil 50.6 years [1]. On the other hand, burning too much coal, oil, and natural gas will release a large amount of carbon dioxide, cause air pollution, and deteriorate global climate warming. These have a serious impact on the environment and life. Satisfying energy requirements and avoiding fuel crises are the current global focus. There is an urgent need to develop sustainable energy to solve these imperative problems. Solar power is a popular sustainable energy source to help solve the energy problem [2, 3].

The dye-sensitized solar cell (DSSC) is one of the most promising potential solar power sources [4-19]. In 1996, Grätzel's research group proposed low-cost novel photovoltaic modules based on monolithically seriesconnected dye sensitized photoelectrochemical cells. The photovoltaic modules were produced in a continuous non-vacuum process by simple printing techniques [20].

In 2008, Kim et al. reported on novel thixotropic gel electrolytes [21]. The novel thixotropic gel electrolytes were prepared by oligomeric poly(ethylene oxide) (PEO)-based bis-imidazolium diiodide salts and hydrophilic silica nanoparticles for application in quasisolid-state DSSCs. A quasi-solid-state DSSC with the proposed electrolyte exhibited highly improved properties, such as easy penetration and long-term stability.

In 2010, Grätzel's group discussed the effect of heat and light on the performance of DSSCs based on organic sensitizers and nanostructured $\mathrm{TiO}_{2}$ [22]. The main reasons for the loss of performance were a decrease in open circuit photovoltage under light soaking conditions and a drop of photocurrent under heat stresses.

The fabrication cost of DSSCs is lower than that of other solar cells, so that the development of DSSCs can greatly reduce the cost of solar power generation [23]. In addition, DSSCs have a low light effect that can also generate electricity in an environment where it is cloudy or sunlight is insufficient. Furthermore, DSSCs are suitable for building materials, such as windows, shades, and glass curtains of buildings. DSSCs can be used to improve the energy efficiency of buildings. Owing to the numerous advantages of DSSCs compared to other types of solar cells, DSSCs are promising in relation to energy generation.

This paper discusses the studies on the advanced manufacturing technology of DSSCs. The key process technologies for DSSCs, including working electrodes,

Corresponding author: yllai@cc.ncue.edu.tw 
dyes, counter electrodes, electrolytes, were investigated. This paper probes into the influence of $\mathrm{TiO}_{2}$ film thickness on photoelectric conversion efficiency of DSSCs.

\section{Experimental}

The structure of the DSSC is shown in Fig. 1. A DSSC consisted of a fluorine-doped tin oxide (FTO) conductive glass substrate, a $\mathrm{TiO}_{2}$ film as a working electrode, a dye, a counter electrode and an electrolytic solution. The structure components of the DSSC were stacked like a sandwich.

\subsection{Preparation of working electrodes}

The working electrode of the DSSC was fabricated by the doctor blade method. $\mathrm{A} \mathrm{TiO}_{2}$ thin film was used for the fabrication of the working electrode of the DSSC.

At first, an invisible tape was pasted on the FTO substrate. The circle area of the tape with an inner radius of $0.5 \mathrm{~cm}$ was cut out. Then, the $\mathrm{TiO}_{2}$ film was coated on the FTO substrate by the doctor blade method. The $\mathrm{TiO}_{2}$ working electrode was placed on a $70-^{\circ} \mathrm{C}$ hot plate for 10 min. The working electrode was then placed in a $450-^{\circ} \mathrm{C}$ high temperature furnace for $20 \mathrm{~min}$ for high temperature sintering. A fabricated $\mathrm{TiO}_{2}$ working electrode is shown in Fig. 2. There were three thickness conditions of $\mathrm{TiO}_{2}$ films, indicated by $\mathrm{A}, \mathrm{B}$, and $\mathrm{C}$, corresponding to one layer, two layers, and three layers of the invisible tape, respectively.

\subsection{Preparation of counter electrodes}

The platinum $(\mathrm{Pt})$ material was used for the fabrication of the counter electrode. The Pt counter electrode was fabricated by the spin coating method.

Firstly, the Pt solution was dropped onto a drilled FTO substrate. Secondly, the Pt was uniformly coated on the FTO substrate with a spin speed of $500 \mathrm{rpm}$ for $90 \mathrm{~s}$ utilizing a spin coater. Finally, the Pt counter electrode was placed in a high temperature furnace at $450{ }^{\circ} \mathrm{C}$ for $30 \mathrm{~min}$ for high-temperature annealing. A fabricated $\mathrm{Pt}$ counter electrode is shown in Fig. 3.

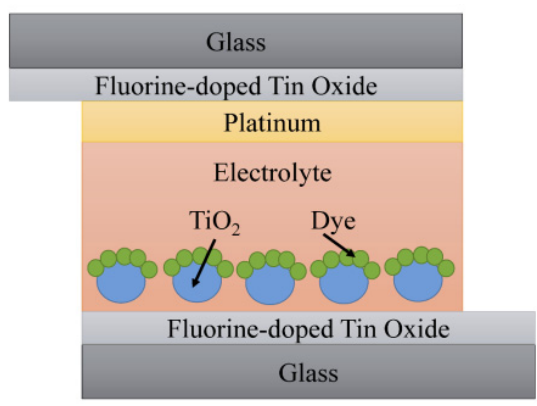

Fig. 1. The structure of DSSCs.

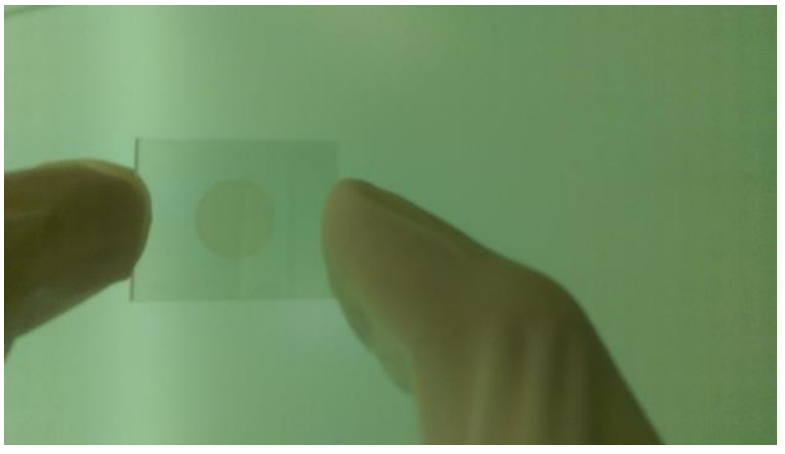

Fig. 2. Fabricated $\mathrm{TiO}_{2}$ film working electrode.

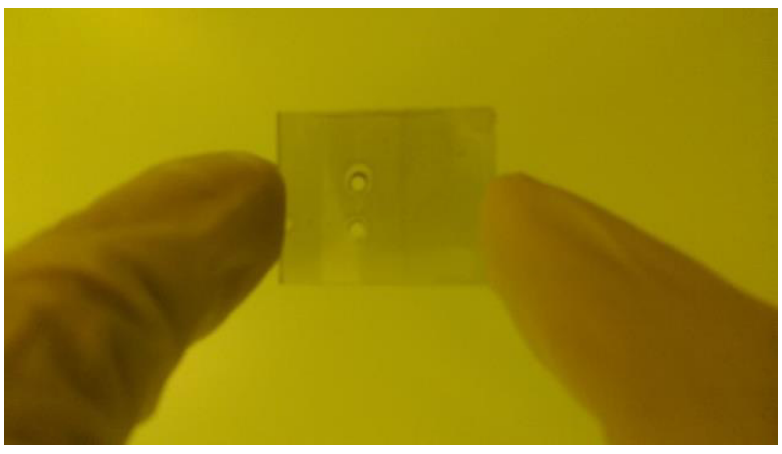

Fig. 3. Fabricated Pt counter electrode.

\subsection{Preparation of dyes}

The chemicals utilized to prepare the dye included N719 dye powders, tert-Butyl alcohol (TBA), and acetonitrile. TBA and acetonitrile were mixed at a ratio of $1: 1$. The dye concentration was $5 \times 10^{-4} \mathrm{~mol} / \mathrm{L}$. The prepared $\mathrm{TiO}_{2}$ working electrodes were then immersed in the prepared dye solution for $24 \mathrm{~h}$.

\subsection{Preparation of electrolyte}

The chemicals utilized to prepare the electrolyte included 0.1 M lithium iodide (LiI), 0.6 M 1,2-dimethyl3-propylimidazolium iodide, $0.005 \mathrm{M}$ iodine $\left(\mathrm{I}_{2}\right)$, and 0.5 $\mathrm{M}$ tert-butylpyridine. These chemicals were added to acetonitrile.

\subsection{Cell assembly}

DSSC components were assembled utilizing a membrane (Surlyn) with an area of $1.5 \mathrm{~cm} \times 1.5 \mathrm{~cm}$ and a thickness of $60 \mu \mathrm{m}$. Firstly, a circle of the membrane with a radius of $0.5 \mathrm{~cm}$ was cut out. Secondly, the membrane was placed on the $\mathrm{TiO}_{2}$ working electrode without covering the $\mathrm{TiO}_{2}$ layer. Thirdly, the counter electrodes were then aligned and stacked on top of the membrane. The stacked components were placed in the heat press sealing machine with the settings of $145-^{\circ} \mathrm{C}$ temperature and $1.5-$ $\mathrm{kg} / \mathrm{mm}^{2}$ pressure. Fourthly, after the stacked components 
of DSSCs were heat press sealed, the electrolyte was then injected through the drilled opening hole of the $\mathrm{Pt}$ counter electrode. Finally, the drilled hole of the $\mathrm{Pt}$ counter electrode was sealed with a $3 \mathrm{M}$ invisible tape. A fabricated DSSC is shown in Fig. 4.

\section{Results and discussion}

The surface morphology of the thin film under various coating conditions was studied by scanning electron microscopy (SEM) analysis. The thickness, uniformity, porosity, and grain size, of the thin film were observed. The SEM photographs of the cross-sectional views of the $\mathrm{TiO}_{2}$ working electrodes fabricated under different conditions are shown in Fig. 5. The thickness values of the $\mathrm{TiO}_{2}$ working electrodes fabricated under the conditions $\mathrm{A}, \mathrm{B}$, and $\mathrm{C}$ are $7.67,18.5$, and $24.3 \mu \mathrm{m}$, respectively.

The light transmittance characteristics of $\mathrm{TiO}_{2}$ working electrodes, fabricated under the conditions A, B, and $\mathrm{C}$, were measured utilizing ultraviolet-visible (UVVis) spectroscopy. The measured light transmittance characteristics are shown in Fig. 6. The light transmittance characteristics of the $\mathrm{TiO}_{2}$ working electrodes fabricated under the conditions $\mathrm{A}, \mathrm{B}$, and $\mathrm{C}$ are $73 \%, 69 \%$, and $66 \%$, respectively, at a wavelength of $850 \mathrm{~nm}$. It was found that the increasing thickness of the $\mathrm{TiO}_{2}$ film reduced the light transmittance of the $\mathrm{TiO}_{2}$ working electrode.

The photovoltaic characteristics of the DSSCs were measured by an AM-1.5 sunlight simulator with a light intensity of $100 \mathrm{~mW} / \mathrm{cm}^{2}$. The photovoltaic characteristics of the DSSCs, including open-circuited voltage $\left(V_{\mathrm{OC}}\right)$, short-circuited current density $\left(J_{\mathrm{SC}}\right)$, fill factor, and photovoltaic conversion efficiency were obtained. Table 1 lists the photovoltaic characteristics of the DSSCs. Fig. 7 shows the photocurrent density versus voltage $(J-V)$ characteristics of the DSSCs. The shortcircuited current density of the DSSCs with the $\mathrm{TiO}_{2}$ working electrodes fabricated under the conditions $\mathrm{A}, \mathrm{B}$, and $\mathrm{C}$ were 16.28, 14.27, and $14.07 \mathrm{~mA} / \mathrm{cm}^{2}$, respectively. The photoelectric conversion efficiency of the DSSCs with the $\mathrm{TiO}_{2}$ working electrodes fabricated under the conditions $\mathrm{A}, \mathrm{B}$, and $\mathrm{C}$ were $6.01 \%, 5.29 \%$, and $4.98 \%$, respectively. It was seen that the increasing thickness of the $\mathrm{TiO}_{2}$ film from 7.67 to 18.5 and $24.3 \mu \mathrm{m}$ decreased the photocurrent density and photovoltaic conversion efficiency of the DSSC.

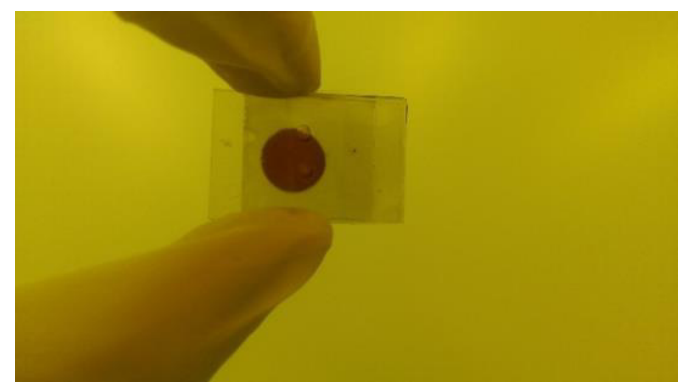

Fig.4. Fabricated DSSC.

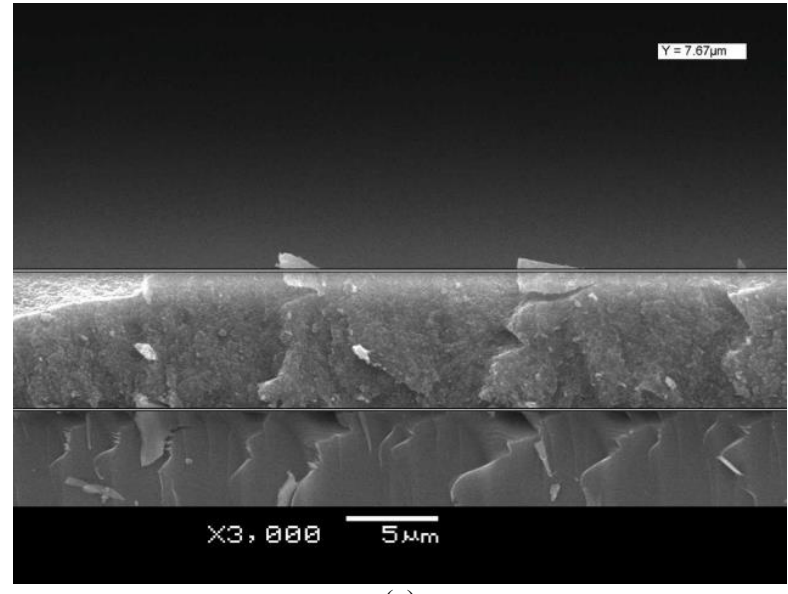

(a)

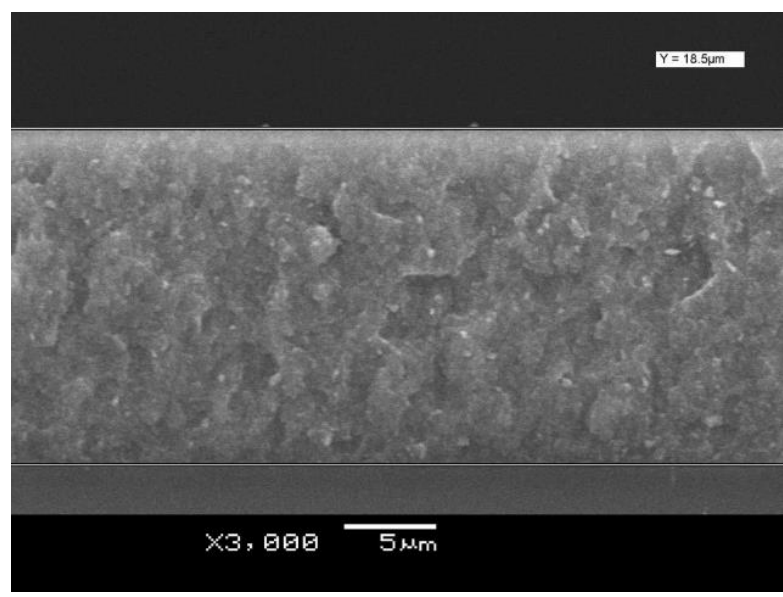

(b)

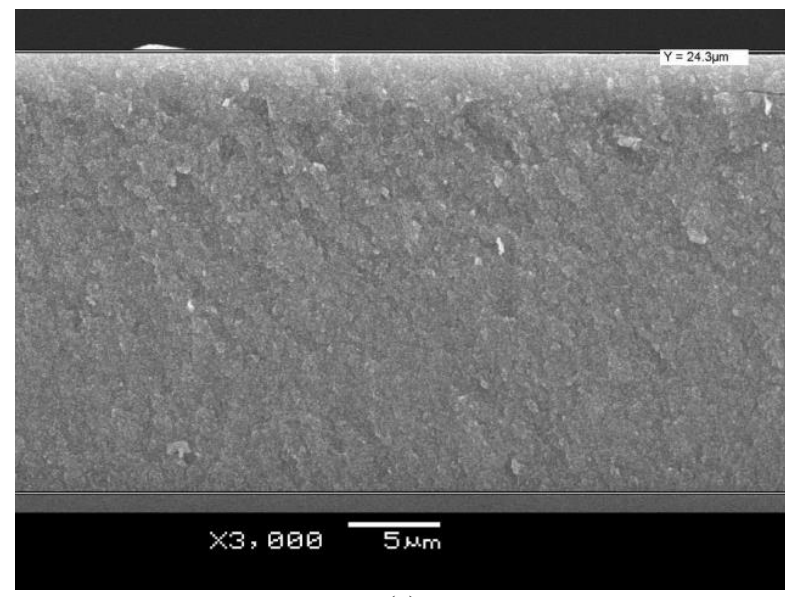

(c)

Fig. 5. Cross-sectional views of the $\mathrm{TiO}_{2}$ working electrodes fabricated under different conditions. (a) condition A, (b) condition B, and (c) condition C.

The thicker $\mathrm{TiO}_{2}$ film resulted in the lower light transmittance. The lower light transmittance reduced the amounts of dye molecules excited by the photons. The fewer dye molecules excited by the photons led to the lower photocurrent density and photoelectric conversion efficiency of the DSSC. 


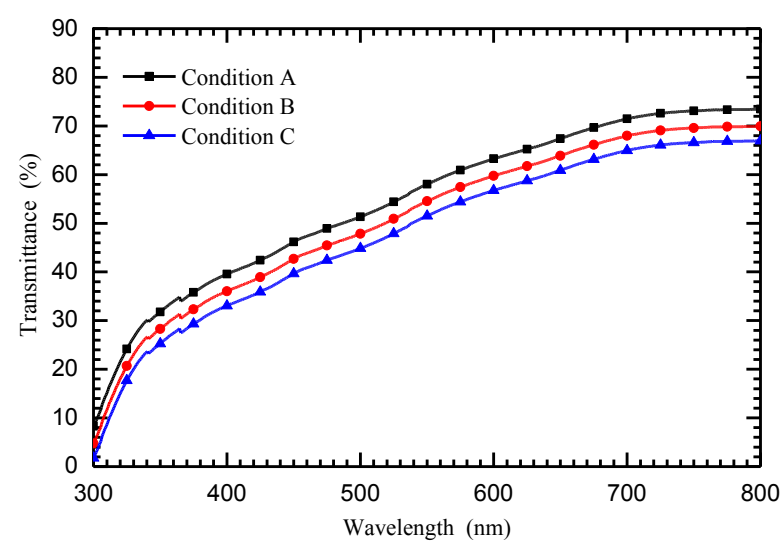

Fig. 6. Light transmittance characteristics of $\mathrm{TiO}_{2}$ working electrodes.

Table 1. Photovoltaic characteristics of DSSCs.

\begin{tabular}{|c|c|c|c|c|}
\hline Condition & $\begin{array}{c}V \mathrm{oc} \\
(\mathrm{V})\end{array}$ & $\begin{array}{c}J_{\mathrm{sc}} \\
\left(\mathrm{mA} / \mathrm{cm}^{2}\right)\end{array}$ & $\begin{array}{c}\text { FF } \\
(\%)\end{array}$ & $\begin{array}{c}\text { Efficiency } \\
(\%)\end{array}$ \\
\hline Condition A & 0.76 & 16.28 & 48.00 & 6.01 \\
\hline Condition B & 0.75 & 14.27 & 48.82 & 5.29 \\
\hline Condition C & 0.73 & 14.07 & 48.32 & 4.98 \\
\hline
\end{tabular}

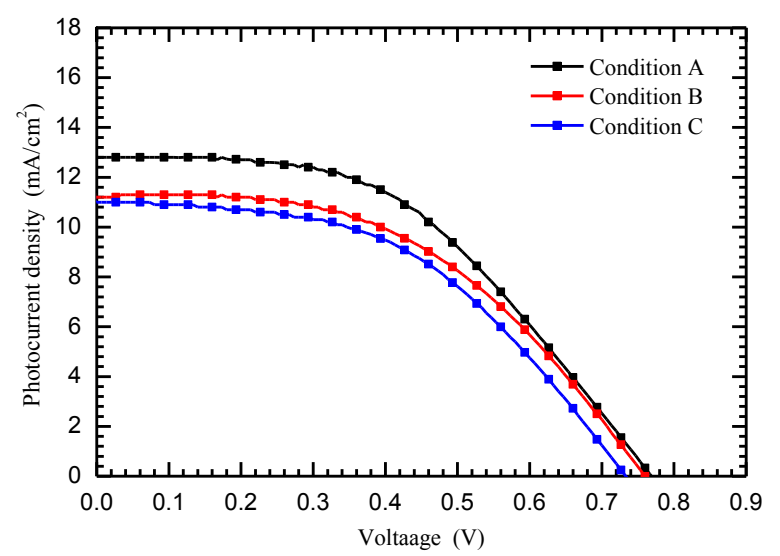

Fig. 7. Photocurrent density versus voltage $(J-V)$ characteristics of the DSSCs.

\section{Conclusion}

The influence of the $\mathrm{TiO}_{2}$ film thickness (from 7.67 to $24.3 \mu \mathrm{m})$ of the working electrodes on the DSSC performance, including $V_{\mathrm{OC}}, J_{\mathrm{SC}}$, fill factor, and photovoltaic conversion efficiency, was studied herein. Both the SEM and UV-Vis were used for the material analysis of the $\mathrm{TiO}_{2}$ working electrodes. The dye of the DSSC used the chemicals of N719 dye powders, TBA, and acetonitrile. The photovoltaic characteristics of the DSSCs were measured by an AM-1.5 sunlight simulator. The relations among the $\mathrm{TiO}_{2}$ film thickness, light transmittance characteristics, and photovoltaic characteristics were investigated. The $\mathrm{TiO}_{2}$ film thickness of the working electrodes affected the light transmittance and the light absorption of the dye, and gave rise to the final photovoltaic conversion properties.

\section{Acknowledgment}

This work was supported in part by the Ministry of Science and Technology of Taiwan, R.O.C. under Contracts MOST 1042221-E-018-016, MOST 105-2218-E-018-001, MOST 1062218-E-018-002, and MOST 106-2218-E-018-003.

\section{References}

1. BP Statistical Review of World Energy June 2017.

2. S. Mozaffari, M. R. Nateghi, M. B. Zarandi, Renew. Sustainable Energy Rev., 71, 675 (2017)

3. S. Sharma, B. Siwach, S.K. Ghoshal, D. Mohan, Renew. Sustainable Energy Rev., 70, 529 (2017)

4. D. M. Chapin, C. S. Fuller, and G. L. Pearson, J. Appl. Phys., 25, 676 (1954)

5. J. M. Nunzi, C. R Phys., 3, 523 (2002)

6. Y.L. Lai, L.Y. Tang, J. Precis. Mach. Manuf. Technol., 6, 1 (2016)

7. K. Hara, K. Sayama, Y. Ohga, A. Shinpo, S. Suga, H. Arakawa, Chem. Comm., 569 (2001)

8. Y.L. Lai, L.W. Chen, C.-H. Chen, Appl. Mech. Mater, 865, 54 (2017)

9. H. Lindström, A. Holmberg, E. Magnusson, S. E. Lindquist, L. Malmqvist, A. Hagfeldt, Nano Lett., 1, 97 (2001)

10. W. Kubo, T. Kitamura, K. Hanabusa, Y. Wada, S. Yanagida, Chem. Comm., 374 (2002)

11. M. Grätzel, J. Photochem. \& Photobio. A: Chem., 164, 3 (2004)

12. Y.L. Lai, Y.H. Huang, Lect. Notes Electr. Eng., 234, 987 (2013)

13. Y. Li, J. Hagen, W. Schaffrath, P. Otschik, D. Haarer, Sol. Energy Mater. Sol. Cells, 56, 167 (1999)

14. K. Srikanth, Md. M. Rahman, H. Tanaka, K.M. Krishna, T. Soga, M. K. Mishra, T. Jimbo, M.Umeno, Sol. Energy Mater. Sol. Cells, 65, 171 (2001)

15. K. Kalyanasundaram, M. Grätzel, Coord. Chem. Rev., 177, 347 (1998)

16. Y.L. Lai, S.H. Chen, J.H. Lu, J.-S. Ting, T.Y. Tsai, Lect. Notes Electr. Eng., 234, 975 (2013)

17. M. S. Suait, M. Y. A. Rahman, A. Ahmad, Sol. Energy, 115, 452 (2015)

18. A. Goetzberger, C. Hebling, H. W. Schock, Mater. Sci. Eng.: R: Rep., 40, 1 (2003)

19. A. I. Kontos, A. G. Kontos, D. S. Tsoukleris, M. C. Bernard, N. Spyrellis, P. Falaras, J. Mater. Process. Technol., 196, 243 (2008) 
20. A. Kay, M. Grätzel, Sol. Energy Mater. Sol. Cells, 44, 99 (1996)

21. J. Y. Kim, T. H. Kim, D. Y. Kim, N.-G. Park, K.-D. Ahn, J. Power Sources, 175, 692 (2008)

22. J.H. Yum, R. Humphry-Baker, S. M. Zakeeruddin, M. K. Nazeeruddin, M. Grätzel, Nano Today, 5, 91 (2010)

23. V. Kislyuk, O. Dimitriev, J. Nanosci. Nanotechnol., 8, 1 (2008) 